ASM Sc. J., 13, 2020

https://doi.org/10.32802/asmscj.2020.sm26(2.3)

\title{
A Study on the Relationship between Students' Computer Self-Efficacy and Use of ICT in Learning Mathematics: The Level of Students' Mathematics Ability as a Mediator
}

\author{
Tahereh Kaboodvand ${ }^{1}$, Tajularipin Sulaiman ${ }^{2 *}$, Ahmad Fauzi Mohd Ayub ${ }^{3}$ \\ ${ }^{1}$ Institute for Mathematical Research, Universiti Putra Malaysia, \\ 43400 UPM Serdang, Selangor, Malaysia. \\ ${ }^{2,3}$ Department of Foundation of Education, Faculty of Educational Studies, Universiti Putra Malaysia, \\ 43400 UPM Serdang, Selangor, Malaysia.
}

\begin{abstract}
In this information age, information, and communication technology (ICT) has changed in the field of education system. While it is important that students have to be able to use ICT in Mathematics classroom. This study discovered the factor that influence on students' computer self-efficacy and use of ICT in learning Mathematics based on their level of Mathematics ability. 120 Mathematics students from the state of Zanjan in Iran were randomly selected from a simple random sampling technique. In this paper the researcher examined the relation between students' computer self-efficacy and students' use of ICT in learning mathematics based on their level of Mathematics ability. Students' computer self-efficacy was positively correlated with the students' use of ICT for learning Mathematics $[\mathrm{r}=.41 ; \mathrm{p}<.001]$. A structural equation modeling (SEM) analysis showed that more than $66 \%$ of the variation in student' use of ICT in the Mathematics classroom was explained by the variation in students' computer self-efficacy based on medium and weak level of Mathematics ability.
\end{abstract}

Keywords: mathematics ability, computer self-efficacy, learning mathematics, information, and communication technology

\section{INTRODUCTION}

Over the past few decades, the impacts of ICT in education have been obvious. Over the course of history, there are many demands to improve and enhance education and, educational reform remains a hotly debated topic today (Ball, 2013). As a result, educators at all levels are now compelled to employ and innovate new methods that support the improvement of the standards of their classroom functions (Roblyer \& Doering, 2010). To students, the benefits increased with the use of ICT are quite immense; however, secondary school students in several countries do not adequately engage with ICT in schools (Smaldino, et. al., 2011).It was reported in the study by Vajargah and Saadattlab (2014) that computers have been in use for administrative purposes in Iranian schools for the past several decades but were inducted into the classroom during the 1990s. In fact, ICT can be used for problem solving and modeling in Mathematics education, and thus, can inspire students to become aware of the relevance of Mathematics activities for their career and academic development (Granberg \& Olsson, 2015). Therefore, great importance has been attributed to the role of computer self-efficacy in influencing students' engagement and use of ICT. Likewise, study by Xu and

*Corresponding author's e-mail: tajulas@upm.edu.my 
Jang (2017) indicated that majority of the scholar in today's research, focused on the direct link between technology related activities for instance, video gameplay, internet use and academic outcomes without considering learners' psychological characteristics, such as selfefficacy. Therefore, understanding students' perception of their ability to use ICT in learning mathematics is quite fundamental to underpinning important strategies for involving students in implementing ICT policies in secondary schools.

\section{A. Students' Computer Self-Efficacy}

Computer self-efficacy as an individual's perceptions of his/her ability to use computer in completing tasks (Ong, et. al., 2004). Other study by Venkatesh and Bala (2008) also defined computer self-efficacy as the control belief of an individual concerning his/her personal ability to use a computer system. It is also referred to as students' general assessment of their mastery of the computer, as well as their competence in the use divergent ICT tools/domains (Hakkarainen et. al., 2000).

Computer self-efficacy is defined as the degree to which an individual believes that he/she can perform a specific task/job using the computer (Compeau \& Higgins, 1995). Studies have shown that students with high level of computer self-efficacy are more likely to challenge themselves and motivate themselves to perform (Bandura, 1994). According to Agarwal, Sambamurthy, and Stair (2000), in conclusion, the difference in findings may be due to the location, samples, background and cultural issues. Consequently, the study in Iran setting can also provide new findings computer self-efficacy. Therefore, understanding students' perception of their ability to use ICT in learning mathematics is quite fundamental to underpinning important strategies for involving students in implementing ICT policies in secondary schools.

\section{B. Students' use of ICT for Learning Mathematics}

ICT usage behaviour is defined as a process by which ICT are put to use in relation to the volume of tasks they are used for (Kim, Jung, \& Lee, 2008). In the context of this study, ICT use is referred to as the extent to which teachers use ICT for the purpose of facilitating students' learning of Mathematics. Moreover, ICT uses in learning mathematics were measured using instrument by selfdeveloped. At the same time, ICT usage is able to transform the dynamics in mathematics classrooms, where teachers can mix lectures and the hands-on Mathematics practices (Nicolete \& Bilessimo, 2017). Literature has highlighted on the significance of using technology in teaching and learning. As a country with a large number of learners, Iran is also interested in utilizing technology in schools (Mohammadi, Abrizah, Nazari, \& Attaran, 2015). Accordingly, there is the intention of the Iranian government to improve the policy of ICT application in the school system. When the system in implemented students in Iran will have the opportunity to experience learning Mathematics with the support of ICT.

\section{Students Level of Mathematics Ability}

The concept of mathematical ability is important for one's personal future career and the development of a nation (Chaman, Beswick \& Callingham, 2014). In this regard, there are good and weak students of mathematics. High achieving mathematics students can execute mathematical procedures, recall relevant mathematics facts, and regulate their activities steadily and repeatedly (Szabo \& Andrews, 2017). Mathematics ability seems to be gender-based too because apparently girls perceived themselves as less able in mathematics (Nix, PerezFelkner \& Thomas, 2015). Personal qualities such as selfcontrol, motivation and mathematics ability contribute to one's mathematics performance (Saritas \& Akdemir, 2009). In short, students' ability in mathematics varies and various factors affect their performance mathematics learning process. However, it is also interesting to know if being weak in mathematics contribute to higher effort in learning other skills.

\section{Objective of the Study}


The main objective of the study is to determine how the level of students' mathematics ability moderate students' computer self-efficacy and students' use of ICT in learning Mathematics. Specifically, the study aims to address the following hypotheses:

H1: Good students have high Mathematics ability on computer self-efficacy in use of ICT for learning mathematics.

H2: Medium students have medium Mathematics ability on computer self-efficacy in use of ICT for learning mathematics.

H3: Weak students have weak Mathematics ability on computer self-efficacy in use of ICT for learning mathematics.

\section{METHODOLOGY}

This research employed a descriptive survey design based on structural equation modelling (SEM) analyses. Data was collected from secondary mathematics students from several secondary schools in Iran-Zanjan. A simple random sampling technique was applied to select 120 mathematics students from 32 secondary school in Iran.

For data collection, the researchers developed an instrument based on information derived from relevant literature. The instrument for the study was a questionnaire consisting of two parts. Part A gathered demographic information of the respondent. To measure the students' use of ICT for learning Mathematics, we developed 11 items. And we adopted items for Students' computer self-efficacy from Venkatesh et. al., (2003) and Hakkarainen et. al., (2000), Except for ICT competencies, participants responded by using a fivepoint Likert scale indicating that they strongly disagreed (1), disagreed (2), slightly agree (3), agreed (4), or strongly agreed (5) with the questionnaire statements.

\section{A. Measurement Model}

The measurement model or confirmatory factor analysis (CFA) is used to find out the links between observed and latent variables. The measurement model could therefore be said to define the way latent or unobserved variables are assessed in terms of the manifest variables (Ho, 2006). Operationalization of constructs is a very important step (Hair, 2014) in the process of ensuring the accuracy of the construct measured. Researchers have a choice of several established scales in attempting to ensure theoretical accuracy. In the first stage of measurement model, internal consistency which is the reliability of each of the constructs was assessed by the Cronbach alpha ( $\alpha$ ) and composite reliability (CR), whilst convergent validity assessed by indicator reliability (factor loading) and average variance extracted (AVE), and discriminant validity was examined. So, study conducted by Hair (2010), indicated that up to seven indices are considered as appropriate criteria for satisfying the model's fitness, namely: Chi-Square, Chi Square/df, CFI, IFI, IGF, GFI and RMSEA). Out of these indices, Chi-Square/df is for parsimonious fit, CFI, IFI, IGF and GFI are for incremental fit and RMSEA is for absolute fit.

\section{B. Confirmatory Factor Analysis for Individual Constructs}

For each construct there is an initial measurement model with the factor loadings of all its items as well as a modified version of it in which items with lower factor loadings were deleted.

\section{Students' use of ICT for learning Mathematics}

At the initial stage Students' use of ICT for learning Mathematics had nine indicators, but the fit indices were below the set standard.

\section{Computer Self-Efficacy}

At the initial stage computer self- efficacy construct had eight indicators, with all the fit indices being very satisfactory (Relative Chi-Sq.=27.654, GFI=.941, $\mathrm{AGFI}=.895, \mathrm{CFI}=.975, \mathrm{IFI}=.975$ and $\mathrm{RMSEA}=.057)$. 


\section{E. Construct Validity}

discriminant validity must be investigated, (Harrington, 2009).

To assess the construct validity of the constructs in the proposed measurement model, their convergent and

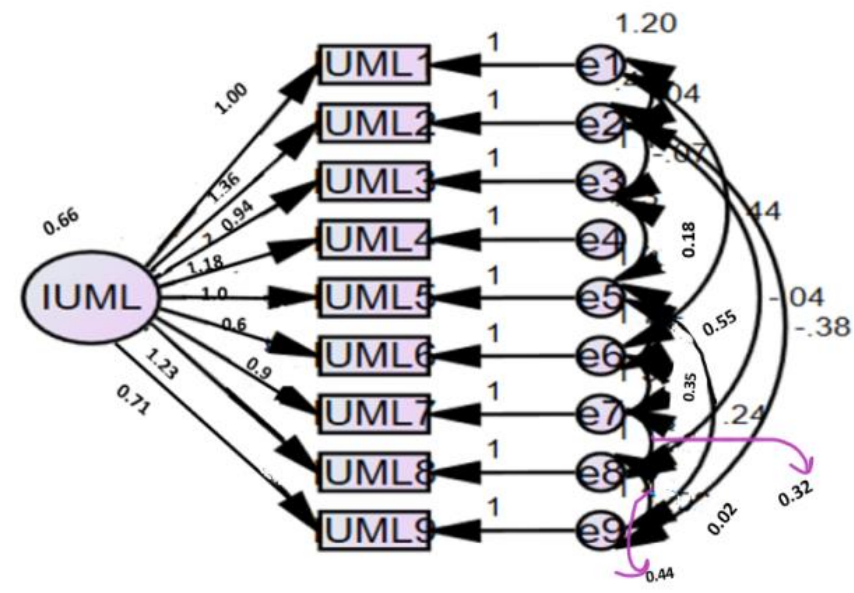

Chi-square $=44.639$

DF $=42$

Relative Chi-sq=1.063

$\mathrm{P}=.361$

$\mathrm{GFI}(>=.9)=.966$

$\operatorname{AGFI}(>=.9)=.932$

$\mathrm{CFI}(>=.9)=.997$

$\mathrm{IFI}(>=, 9)=.997$

$\mathrm{NFI}(>=.9)=.949$

Rmsem $(<=.08)=.013$

Figure 1. Initial Measurement Model for ICT use in learning Mathematics

Table 1. Fit Indices of the Revised Measurement Model for ICT use in learning Mathematics

\begin{tabular}{cccc}
\hline Fit Indices & Index Value & Recommended Value & Results \\
\hline Relative Chi-Sq & 1.063 & $\leq 5.00$ & Good Fit \\
\hline GFI & .966 & $\geq 0.90$ & Good Fit \\
\hline AGFI & .932 & $\geq 0.90$ & Good Fit \\
\hline CFI & .997 & $\geq 0.90$ & Good Fit \\
\hline IFI & .997 & $\geq 0.90$ & Good Fit \\
\hline NIF & .949 & $\geq 0.90$ & $\leq 0.08$ \\
\hline RMSEA & .013 & Good Fit
\end{tabular}

GFI: Goodness of Fit Index; AGFI: Adjusted Goodness of Fit Index; CFI: Comparative Fit Index; IFI: Incremental Fit Index; NFI: Normed Fit Index; RMSEA: Root Means Squared Error of Approximation 

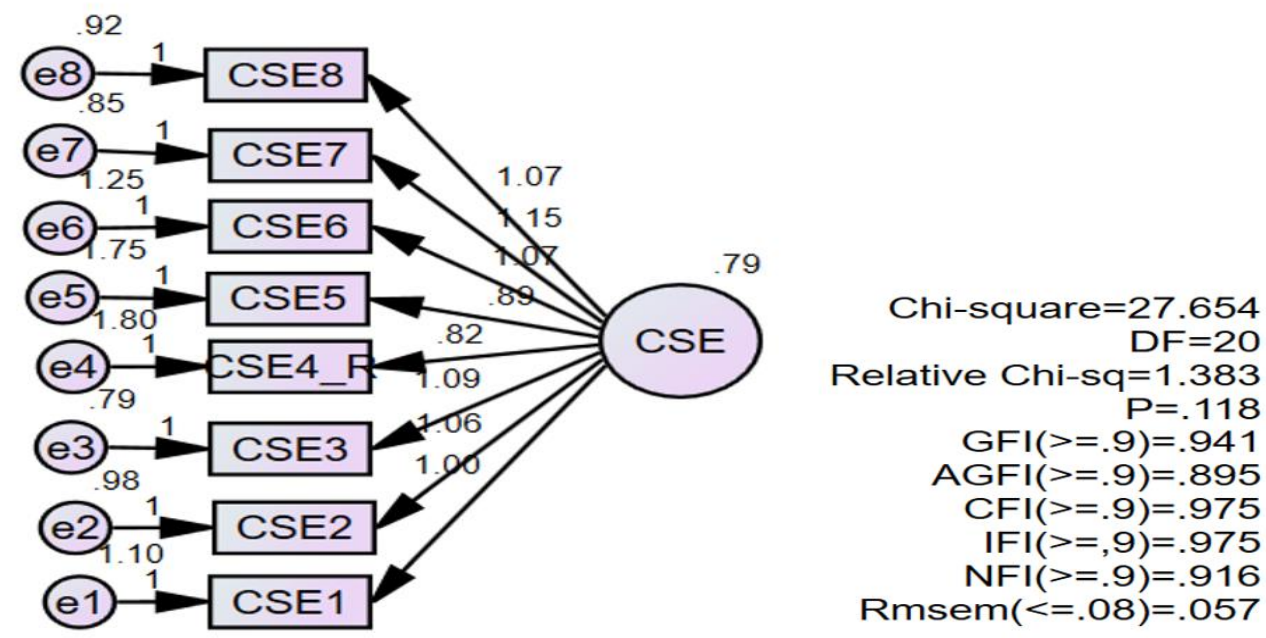

Figure 2. Initial Measurement Model for computer self-efficacy

Table 2. Fit Indices of the Revised Measurement Model for computer self- efficacy

\begin{tabular}{cccc}
\hline Fit Indices & Index Value & Recommended Value & Results \\
& & $\leq 5.00$ & Good Fit \\
\hline Relative Chi-Sq & 1.383 & $\geq 0.90$ & Good Fit \\
\hline GFI & .941 & $\geq 0.90$ & Good Fit \\
\hline AGFI & .895 & $\geq 0.90$ & Good Fit \\
\hline CFI & .975 & $\geq 0.90$ & Good Fit \\
\hline IFI & .975 & $\leq 0.08$ & Good Fit
\end{tabular}

GFI: Goodness of Fit Index; AGFI: Adjusted Goodness of Fit Index; CFI: Comparative Fit Index; IFI: Incremental Fit Index; NFI: Normed Fit Index; RMSEA: Root Means Squared Error of Approximation

Table 3. Factor Loadings, AVE of items in the Initial Overall Measurement Model

\begin{tabular}{|c|c|c|c|}
\hline Construct & Item & Factor Loading & $\operatorname{AVE}(\geq 0.5)$ \\
\hline \multirow[t]{6}{*}{ Students' use ICT for learning Mathematics } & IULM1 & 1.00 & .87 \\
\hline & IULM2 & 0.96 & \\
\hline & IULM3 & 0.89 & \\
\hline & IULM4 & 1.13 & \\
\hline & IULM5 & 1.07 & \\
\hline & IULM6 & 0.93 & \\
\hline
\end{tabular}




\begin{tabular}{|c|c|c|c|}
\hline Construct & Item & Factor Loading & $\operatorname{AVE}(\geq 0.5)$ \\
\hline & IULM7 & 1.35 & \\
\hline & IULM8 & 1.42 & \\
\hline & IULM9 & 1.32 & \\
\hline \multirow[t]{9}{*}{ Computer Self-Efficacy } & & & .88 \\
\hline & CSE1 & 0.94 & \\
\hline & CSE2 & 0.89 & \\
\hline & CSE3 & 0.90 & \\
\hline & CSE4_R & 0.97 & \\
\hline & CSE5 & 1.00 & \\
\hline & CSE6 & 0.94 & \\
\hline & CSE7 & 1.00 & \\
\hline & CSE8 & 0.86 & \\
\hline
\end{tabular}

According to table three, it indicated that for each construct, factor loading is 0.7, AVE is $\geq 0.5$. As rooted by Hair (2010), the criterion value accepted for a valid AVE is $\geq 0.5$

\section{F. Convergent Validity}

Study conducted by Hair et. al., (2010), to have convergent validity on a construct its factor loadings should be $\geq 0.5$.According to Hair et al. (2010), the criterion value accepted for a valid AVE is $\geq 0.5$. The value is calculated through the following formula:AVE $=\frac{\Sigma \lambda^{2}}{n}$

Where:

$\lambda^{2}=$ Squared factor loading

$\mathrm{n}=$ Number of indicators

\section{FINDINGS}

The purpose of this section is to interpret the coefficients of determination and prediction of the exogenous variable over the endogenous variable based on their level of Mathematics ability. The standardized and unstandardized regression weights ( $\beta$ and b respectively) for the proposed structural model. According to the figure 3 as we mentioned about the level of students ability in Mathematics in 3 level good, average and weak in the first level computer self-efficacy(CSE) is not a predictor factor for students ICT use for Mathematics learning (IUML) based on students' mathematics ability. On the other hand, their higher Mathematics ability grant them to use ICT in Mathematics classroom simply and they do not require to be prepared for the use of ICT in Mathematics classroom. Furthermore, students with average and lower level of Mathematics ability require having computer selfefficacy (CSE) to use ICT for learning Mathematics. As noted, students with mathematics ability in good level no need computer self-efficacy to use ICT tools in Mathematics class.

Table four, indicates that students in Level one of Mathematics ability does not moderate between computer self-efficacy and ICT use in mathematic learning. However, for Level two and three Mathematics ability moderates between computers self-efficacy and ICT use in mathematic learning. 


\section{DISCUSSION}

This study explains the relationship between computer self-efficacy and students use of ICT in learning Mathematics based on their level of mathematic ability, good students, average students and weak students. The results of CSE for the first level of CSE (good students) is not significant. This means CSE is not predicting factor on students' use of ICT for learning Mathematics for this group of students. In other words, CSE is not actually function as innovative new support for the the improvement of the students' standard as suggested by Roblyer and Doering (2010). In short, students with higher mathematics ability do not need to have CSE because they can learn to use ICT by themselves. They can learn operate and even modify the operations of the program themselves. Their higher Mathematics ability allows them to use ICT in Mathematics classroom easily and they do not need to be prepared for it.

On the contrary, students with average and lower level of Mathematics ability need to have CSE to use ICT for learning mathematics. Computer self-efficacy (CSE) has higher influence on these students in ICT for learning Mathematics. This is in line with the findings of Nicolete \& Bilessimo (2017) and Mohammadi et. al., (2015). At the same time, average and weaker students need to have higher confidence in ICT use. If their CSE is high in ICT use in learning Mathematics, they are more likely to challenge and motivate themselves to perform better as suggested by Bandura (1994), and they will be more able to handle specific task as suggested by Compeau \& Higgins (1995). CSE make them more aware that ICT could assist them in their mathematics learning as reported by (Granberg \& Olsson, 2015). 


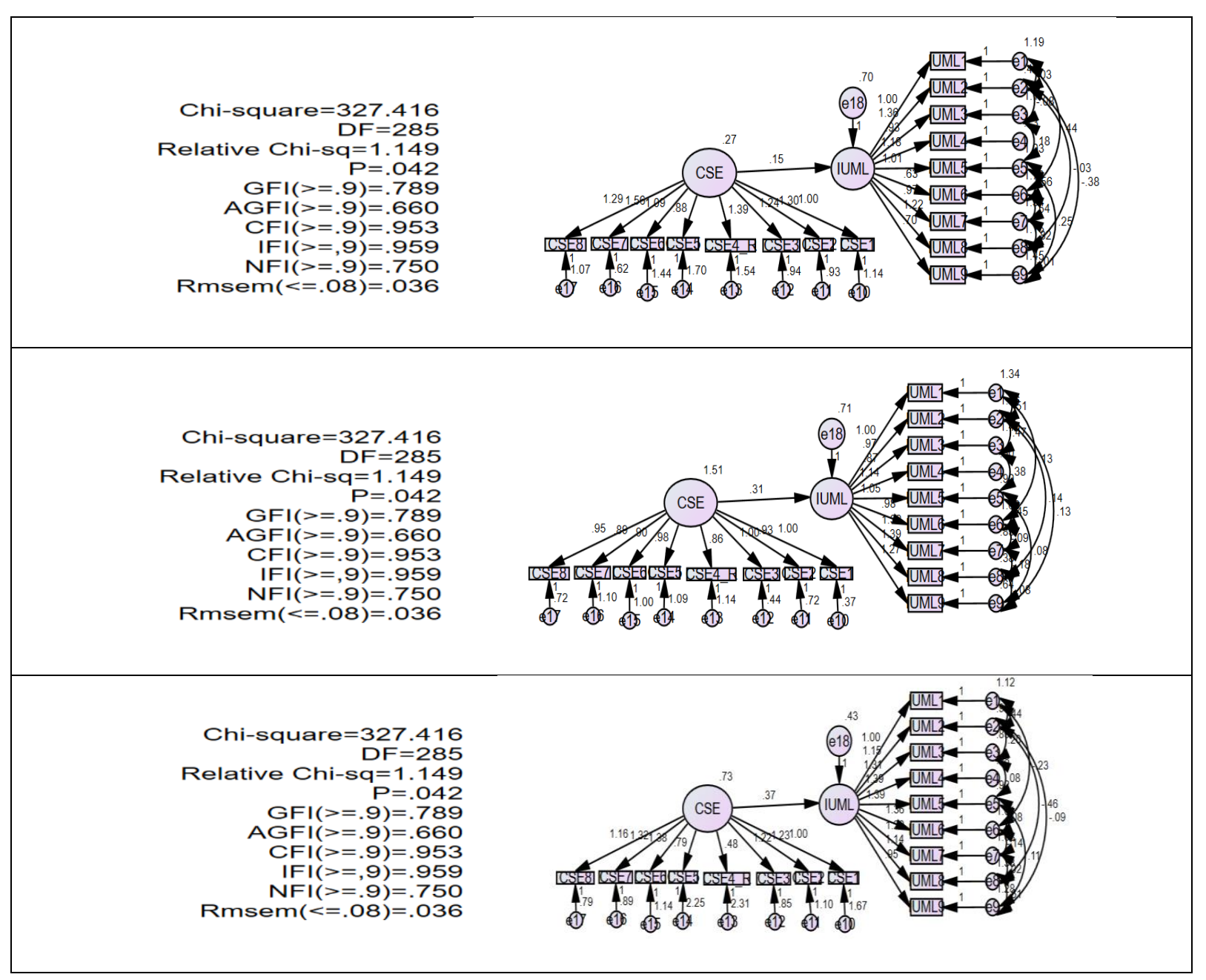

Figure 3. Structural Model with Standardized Estimates in level1,2 and 3 respectively

Table 4. Unstandardized and Standardized Regression Weights for the Structural Model

\begin{tabular}{llllllll}
\hline Paths & $\boldsymbol{b}$ & S.E & C.R & $\boldsymbol{\beta}$ & P-Level & $\mathbf{R}^{2}$ & Results \\
\hline CSE_L1 $\rightarrow$ IULM & .146 & .303 & 3.981 & .096 & 0.620 & 0.090 & Not Supported \\
\hline CSE_L2 $\rightarrow$ IULM & .365 & .199 & 3.062 & .429 & $* * *$ & 0.288 & Supported \\
\hline CSE_L3 $\rightarrow$ IULM & .314 & .151 & 18.384 & .417 & $* * *$ & 0.238 & Supported
\end{tabular}

S.E: Standard Error of regression Weight; C.R: Critical Ratio for regression Weight; p: Level of significance, ${ }^{* * *} \mathrm{p}<$. .oo1 


\section{CONCLUSION}

It is important to ensure students have appropriate level of self-efficacy in ICT use before introducing ICT in mathematics classrooms. Specific stretegies should be designed to enhance This is especially crucial for average and weaker students. earning in mathematics learning especially among average and weaker mathematics students.

\section{REFERENCES}

Agarwal, R., Sambamurthy, V., \& Stair, R. M. 2000, Research report: the evolving relationship between general and specific computer self-efficacy-an empirical assessment. Information systems research, 11(4), 418-430.

Ball, S. J. (Ed.). 2013, Foucault and education: Disciplines and knowledge. Routledge.

Chaman, M.J., Beswick, K. \& Callingham, R., in N. Fitzallen et al., (Eds.), 2014, The Future of Educational Research. Sense Publishers, 227-238.

Compeau, D. R., \&Higgins, C. A. 1995, Computer selfefficacy: Development of a measure and initial test. MIS quarterly, 189-211.

Granberg, C., \& Olsson, J. 2015, ICT-supported problem solving and collaborative creative reasoning: Exploring linear functions using dynamic mathematics software. The Journal of Mathematical Behavior, 37, 48-62.

Hakkarainen, K., Ilomäki, L., Lipponen, L., Muukkonen, H., Rahikainen, M., Lakkala, M., \& Lehtinen, E. 200o, Students' skills and practices of using ICT: Results of a national assessment in Finland. Computers \& Education, 34(2), 103-117.

Harrington, D. 2009, Confirmatory factor analysis. Oxford University Press.

Hair, J. F. 2010, Multivariate data analysis. New Jersey, Pearson College Division.

Kim, J. H., Jung, S. Y., \& Lee, W. G. 2008, Design of contents for ICT literacy in-service training of teachers in Korea. Computers \& Education, 51(4), $1683-1706$.
Madsen, H. O., Krenk, S., \& Lind, N. C. 2006, Methods of structural safety. Courier Corporation.

Mohammadi, F., Abrizah, A., Nazari, M., \& Attaran, M. 2015, What motivates high school teachers to use web-based learning resources for classroom instruction? An exploratory case study in an Iranian smart school. Computers in Human Behavior, 51, 373-381.

Nicolete, P. C., Sommer Bilessimo, S. M., Silva Cristiano, M. A., Schardosim Simao, J. P., \& Silva, J. B. 2017, Technology Integration Actions in Mathematics teaching in Brazilian Basic Education: Stimulating STEM disciplines. RED-Revista de Educación a Distancia, 52.

http://www.um.es/ead/red/52/nicolete_et_al.pdf

Nix, S., Perez-Felkner, L.\& Thomas, K. 2015, Perceived mathematical abilitity under challenged: A longitudinal perspective on sex segregation among STEM degree fields, Vol. 6:530.

Ong, C.-S., Lai, J.-Y., \& Wang, Y.-S. 2004, Factors affecting engineers' acceptance of asynchronous elearning systems in high-tech companies. Information \& management, 41(6), 795-804.

Roblyer, M., \& Doering, A. 2010, What is Educational Technology.

Smaldino, S. E., Lowther, D. L., \& Russell, J. D. 2011,. Thirty Years of Evolution in Instructional Technology, as Reflected in a Textbook. Educational Technology, 51(6), 43-47.

Saritas, T. \& Akhmeri, O. 2009, Identifying Factors Affecting the Mathematics Achievements of Students for Better Educational Design. 
Instructional Technology \& Distance Learning, 6(12)

Sarstedt, M., Ringle, C. M., Smith, D., Reams, R., \& Hair, J. F. 2014, Partial least squares structural equation modeling (PLS-SEM): A useful tool for family business researchers. Journal of Family Business Strategy, 5(1), 105-115.

Szabo, A. \& Andrews, P. 2017, Examining the interaction of mathematical abilities and mathematyical memory: A study of problem-solving activity of high-achievingSweddish upper secondary students. The Mathematics Enthusiast. 14 (1), 141159.

Venkatesh, V., Morris, M. G., Davis, G. B., \& Davis, F. D. 2003, User acceptance of information technology: Toward a unified view. MIS quarterly, 425-478.

Vajargah, K. F., \& Saadattlab, A. 2014, A feasibility study of using ict in Iranian secondary schools: The case of Tehran province.TOJET: The Turkish Online Journal of Educational Technology, 13(3), 1-11.

Xu, Z., \& Jang, E. E. 2017, The role of math self-efficacy in the structural model of extracurricular technology-related activities and junior elementary school students' mathematics ability. Computers in Human Behavior, 68, 547-555.

Zimmerman, B. J. \& Bandura, A. 1994, Impact of self regulatory influences on writing course attainment. American Educational Research Journal, 31(4), $845^{-862 .}$ 